\title{
Structural Analysis of ZnO Film Deposited by Means of Metal Organic Decomposition Method
}

\author{
Masato Ohmukai ${ }^{1}$, Takuya Nakagawa' ${ }^{2}$, Masaru Kamano ${ }^{3}$, Nobutomo Uehara ${ }^{3}$ \\ ${ }^{1}$ Department of Electrical and Computer Engineering, Akashi College of Technology, Akashi, Japan \\ ${ }^{2}$ Technical Education Support Center, Akashi College of Technology, Akashi, Japan \\ ${ }^{3}$ Department of Electrical and Electronic Engineering, Anan National College of Technology, Anan, Japan \\ Email: ohmukai@akashi.ac.jp
}

Received 15 September 2014; revised 17 October 2014; accepted 2 November 2014

Copyright (C) 2014 by authors and Scientific Research Publishing Inc.

This work is licensed under the Creative Commons Attribution International License (CC BY). http://creativecommons.org/licenses/by/4.0/

cC) (i) Open Access

\begin{abstract}
ZnO films were deposited on glass substrates by means of a metal organic decomposition (MOD) method. We investigated the effect of annealing temperature, time and the number of laminated layers on the film structure on the basis of $\mathrm{X}$-ray diffraction measurements. We found the optimum conditions of the temperature and the time to be $600^{\circ} \mathrm{C}$ and 40 minutes for the preparation, respectively. In addition, the layer-by-layer forming was not found to degrade the film from viewpoint of X-ray line width.
\end{abstract}

Keywords

ZnO Film, MOD Method, Transparent Electrode, X-Ray Analysis

\section{Introduction}

$\mathrm{ZnO}$ attracts much attention for the application as a transparent conducting material in the first place [1] [2]. It is expected to replace indium tin oxide, for $\mathrm{ZnO}$ does not include any rare metal element, which is a big advantage for low price from the commercial point of view. As a transparent conducting material, several percent of another element such as aluminum is to be doped. $\mathrm{ZnO}$ is a II - VI semiconductor on the other hand, where it has a direct wide band gap of $3.37 \mathrm{eV}$ at room temperature. So it is quite interesting, at the same time, as a semiconductor material for such applications as thin-film transistors [3] [4], light-emitting diodes [5] [6] and gas sensors [7] [8]. Recently, $\mathrm{ZnO}$ nano-particles are applied to dye-sensitized solar cells for the enhancement of 
energy conversion efficiency [9]. Other optical and electronic properties of $\mathrm{ZnO}$ are summarized in detail in a comprehensive review reported in 2005 [10].

The deposition methods for $\mathrm{ZnO}$ on a substrate are also summarized in the review [10]. The typical methods are radio frequency magnetron sputtering, molecular-beam epitaxy, pulsed-laser deposition and chemical-vapor deposition methods, which are well-known standard methods for electronic device fabrication. However, they all require a vacuum environment for the deposition of the material, which takes long time and high cost for manufacturing. So it is desired to fabricate $\mathrm{ZnO}$ films under the atmosphere. One solution for that is a simple method called the metal-organic decomposition (MOD) method. Using this method, a starting material in viscous liquid is spread over a substrate surface and then annealed to decompose it to form an end material, $\mathrm{ZnO}$ for example. The problem of this method is the relatively low crystalline quality. In this article, we report on the investigation of crystalline quality of $\mathrm{ZnO}$ formed by the MOD method. Guo et al. have achieved the film on glass substrate that shows strong cathode luminescence at room temperature [11]. Zou et al. have studied thermochemical process in $\mathrm{ZnO}$ during thermal treatments and observed the excess weight loss of $\mathrm{ZnO}$ by thermo-gravimetry differential thermal analysis [12]. In this article we focus on the relationship between preparation conditions during thermal treatment and crystalline characteristics in the scope of X-ray diffraction.

\section{Experimental Details}

We used two kinds of glass plates made of borosilicate or soda-lime glass as a substrate. Over the substrate we spread commercially available precursor solution for ZnO (SYM-ZN20, Kojundo Chemical Laboratory) by barcoating method, which was diluted twice in volume with diluent prepared by the same company before the use. The nominal value of the formed film was $23 \mu \mathrm{m}$.

After the film was spread, the sample was prebaked at $120^{\circ} \mathrm{C}$ for 5 minutes to dry out solvent. We performed the heat treatment with an electric furnace in the air. The temperature, duration time and repeat count were varied respectively. For the temperature variation, the temperature was chosen from $300^{\circ} \mathrm{C}$ to $700^{\circ} \mathrm{C}$ where the duration time was 30 minutes. In this experiment, we used a borosilicate glass plate because soda-lime glass was softened above $600^{\circ} \mathrm{C}$. In order to investigate the duration time dependence, the duration time was varied from 10 to 60 minutes where the temperature was fixed to $550^{\circ} \mathrm{C}$. In this case we used a soda-lime glass. Finally, for the layer-by-layer formation of a thicker film, we varied repeat count from 2 to 8 times, where each heat treatment was done for 20 minutes at $550^{\circ} \mathrm{C}$. The substrate used in this experiment was soda-lime glass plates.

The obtained samples were examined by means of an X-ray diffractometer and the surface was observed with a scanning electron microscope (SEM). The X-ray powder diffraction pattern was taken with a diffractometer (Ultima IV, Rigaku) equipped with a $\mathrm{Cu}$ target. SEM photographs were taken with a microscope of JSM6510LA (JEOL Ltd).

\section{Results and Discussion}

Figure 1 shows X-ray diffraction patterns with the variation of temperature. The pattern tells us that the film consists of polycrystalline $\mathrm{ZnO}$. Typical three structures appear at $31.8,34.3$ and 36.5 degrees in the low $2 \theta$ region, corresponding to (100), (002) and (101) planes of $\mathrm{ZnO}$, respectively. Other two structures corresponding to (102) and (110) planes at 47.5 and 57.1 degrees are hard to observe in the figure. We pay attention to the strongest structure at 36.5 degrees. The intensity of this structure is shown in Figure 2 as a function of heat treatment temperature. The intensities are only scattered randomly and does not show any systematic tendency. On the other hand, the full width at half maximum (FWHM) of the structure (Figure 3) monotonically decreases with the temperature. The reduction of the FWHM possibly derives from the enhancement of the crystalline quality or the larger size of crystal grains for instance. The FWHM at $700^{\circ} \mathrm{C}$ is slightly larger than that at $600^{\circ} \mathrm{C}$. It seems to be due to many cracks originated at $700^{\circ} \mathrm{C}$ as shown in the SEM photograph in Figure 4, while there is no surface structure on the sample and then the surface is quite smooth in case of $600^{\circ} \mathrm{C}$.

We next consider the results when the time duration of heat treatment was varied. X-ray patterns are shown in Figure 5. In this figure, the three structures are clearly observed as well as in Figure 1; the two other structures are also weakly observed in addition at 47.5 and 57.1 degrees. In order to discuss the results, we show the integrated intensity and FWHM of the prominent diffracted peak from (101) plane in Figure 6 and Figure 7, respectively. Figure 6 shows the intensity abruptly increases above 20 minutes and the largest at 40 minutes, and 


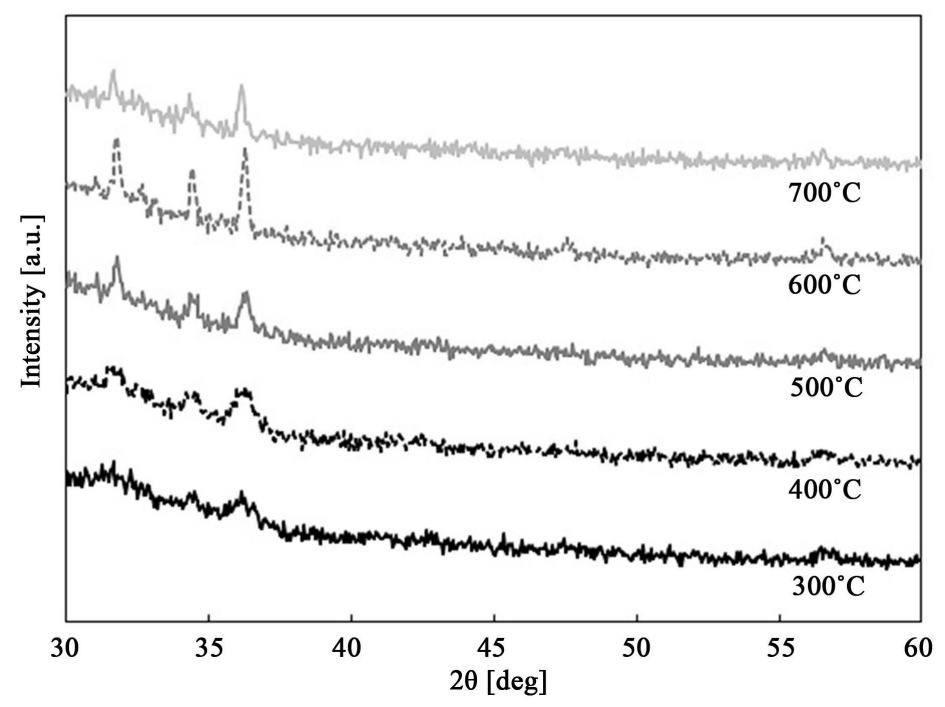

Figure 1. X-ray diffraction patterns from sample prepared at several temperatures.

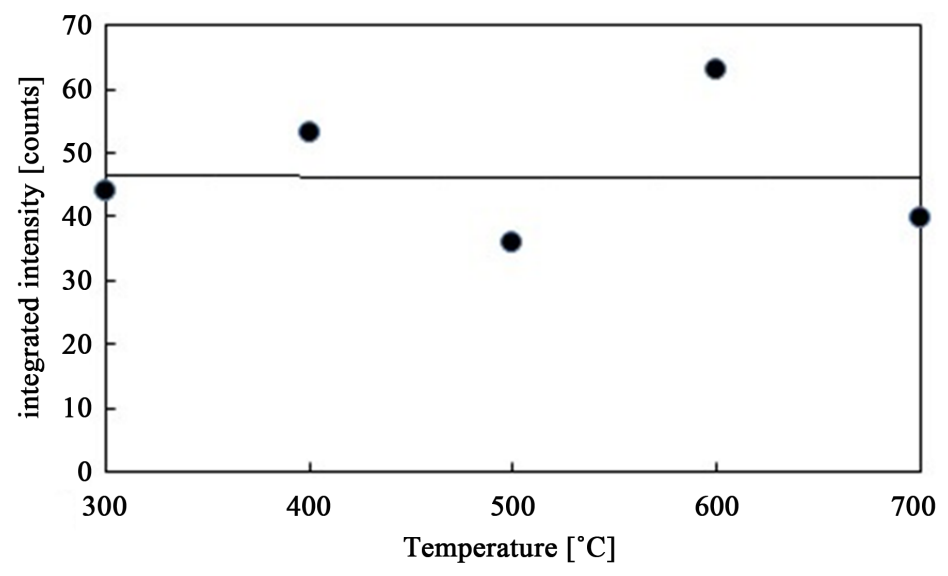

Figure 2. X-ray intensity of (101) diffraction from $\mathrm{ZnO}$ layer as a function of the temperature during heat treatment.

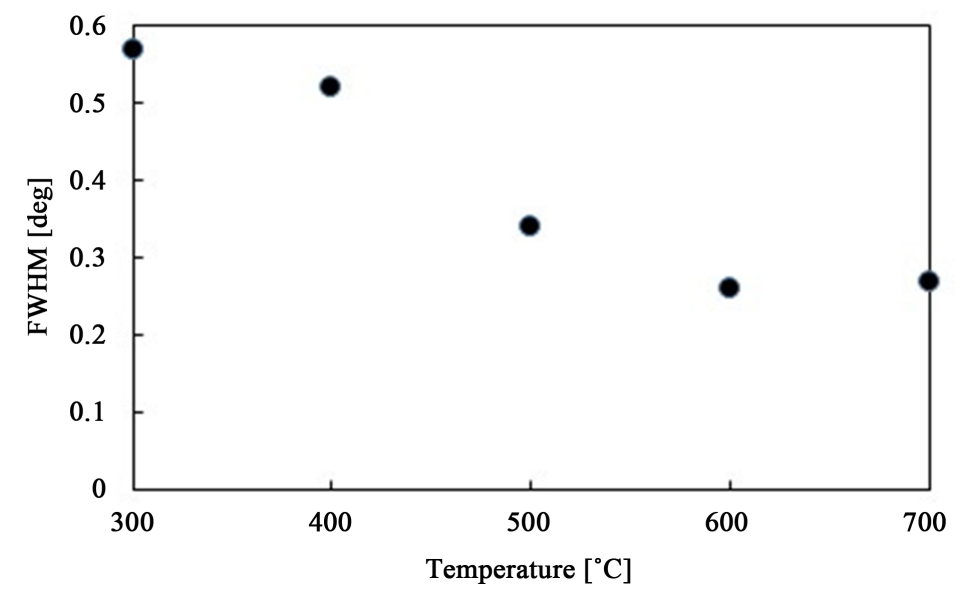

Figure 3. The FWHM of (101) X-ray diffraction structure from $\mathrm{ZnO}$ layer as a function of the temperature during heat treatment. 


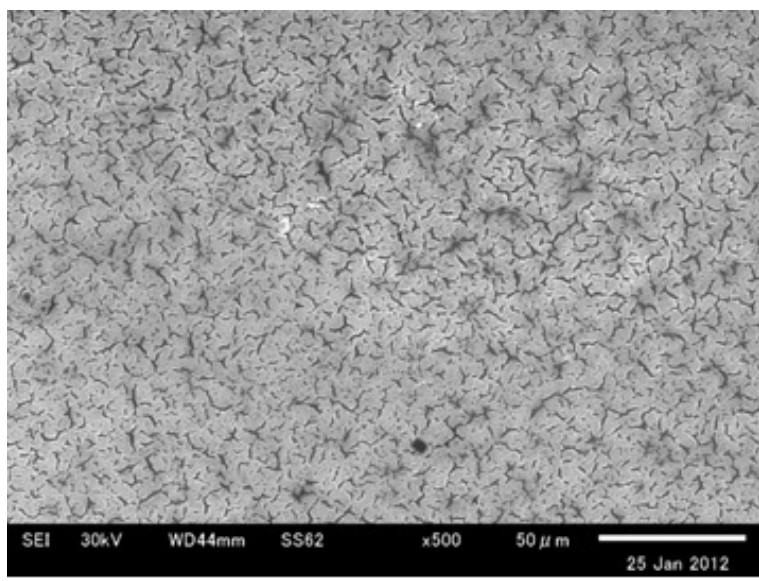

Figure 4. SEM photograph of the sample surface that was prepared at $700^{\circ} \mathrm{C}$.

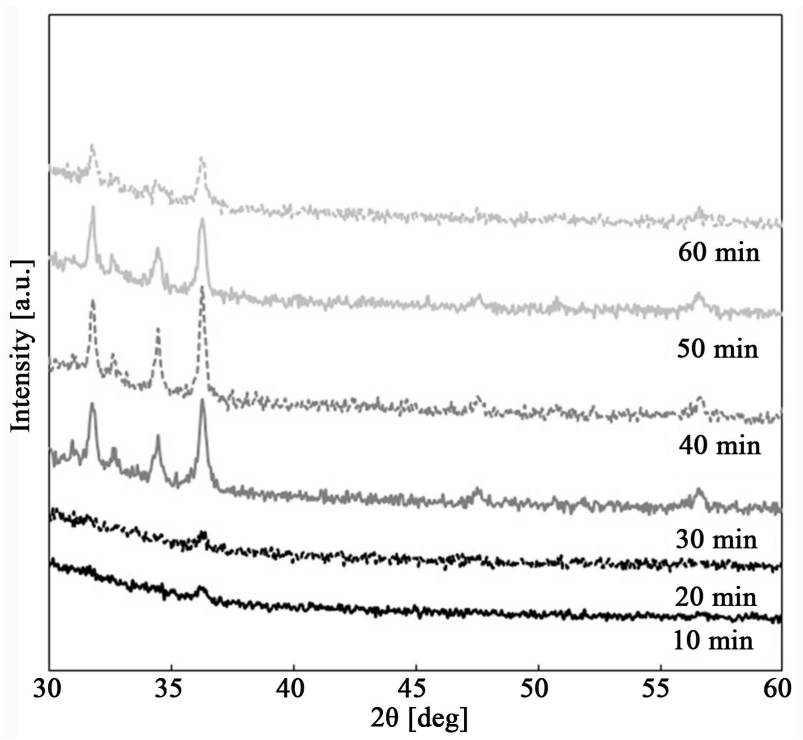

Figure 5. X-ray diffraction patterns from sample prepared at several time durations.

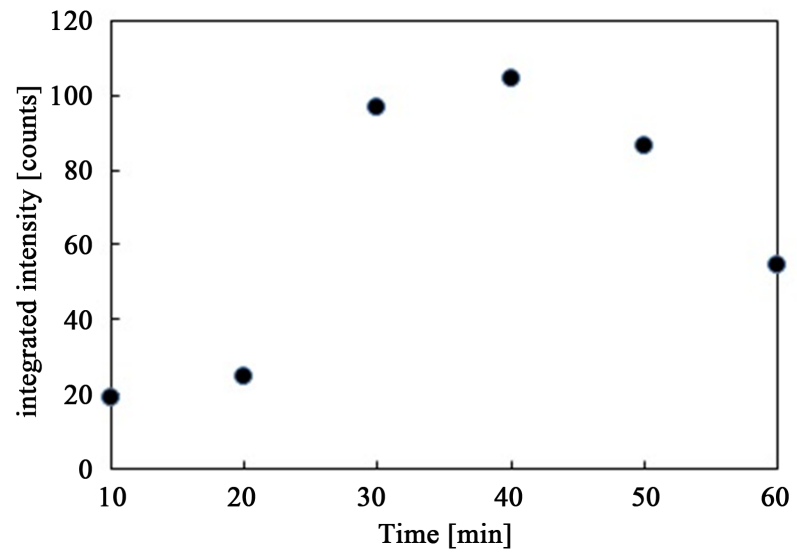

Figure 6. X-ray intensity of (101) diffraction from $\mathrm{ZnO}$ layer as a function of the time duration during heat treatment. 


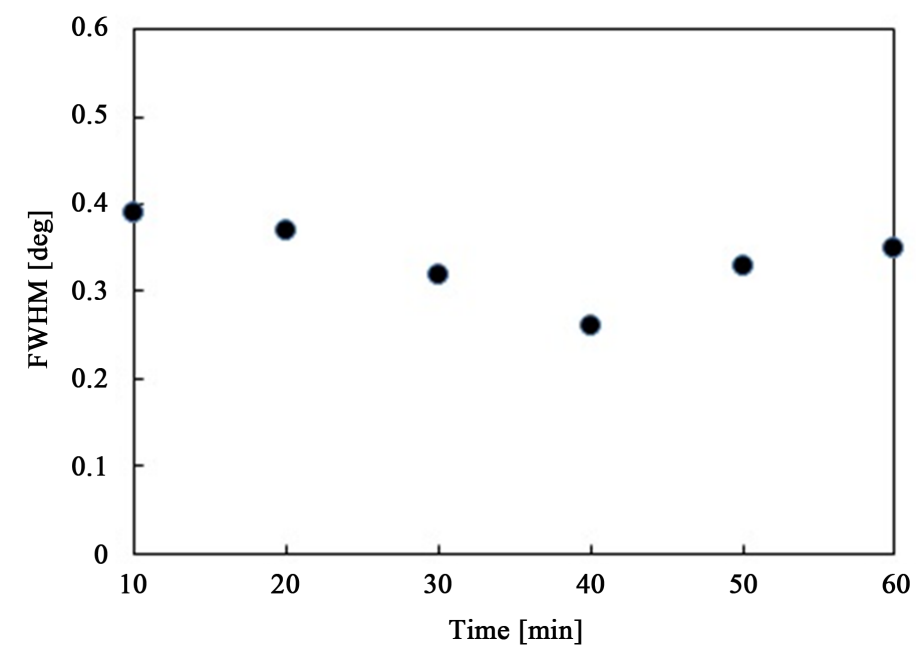

Figure 7. The FWHM of (101) X-ray diffraction structure from $\mathrm{ZnO}$ layer as a function of the time duration during heat treatment.

then decreases gradually with time. The FWHM is the smallest at 40 minutes as shown in Figure 7 . So the time of heat treatment is desirable to be 40 minutes.

We consider the reason of the decrease in X-ray intensity above 40 minutes here. We should pay attention to the fact that not only X-ray diffracted from (101) plane was weakened but all the other structures reduced with time above 40 minutes that can be confirmed in Figure 5. We can then exclude the possibility for the preferred orientation of crystallites to change during the heat treatment. We suppose that whole amount of $\mathrm{ZnO}$ decreases with time above 40 minutes. Since the decomposition temperature of $\mathrm{ZnO}$ is above $1900^{\circ} \mathrm{C}$, the decrease in $\mathrm{X}$ ray intensity is not seemed due to the decomposition.

It should be pointed out that there is no other structure that increases with time over 40 minutes. This means that the other substance was not chemically generated from $\mathrm{ZnO}$. The decrease in X-ray intensity is assumed due to phase changes to amorphous state with the help of the glass substrate. In order to confirm the reason for the $\mathrm{X}$-ray decrease clearly, it is helpful to identify the formation of an amorphous phase by further experiments.

Finally we show X-ray diffraction patterns in case of changing repetition times of successive forming of the film in Figure 8. The intensity and FWHM of (101) diffraction peak are shown in Figure 9 and Figure 10, respectively. The intensity drastically increases with the pile of forming process. On the other hand, the FWHM slightly decreases with the pile of process. The results confirm that the laminating formation process can be effective to obtain a thick film without deteriorating crystalline quality. The laminating forming process is applicable because the starting material is liquid and then it is inconvenient to make a thick layer at one step. Figures 11-14 show the SEM photographs of the surface. The 8-times sample exhibits the largest grains around several micrometers closely packed all over the surface.

The next interesting point is the optical and electrical properties of the $\mathrm{ZnO}$ film. For example, transparency is a major issue for the application for transparent electrodes as well as the resistivity of the film. In this application, single crystal is not required like the materials for active devices such as transistors. The low production cost is rather crucial.

\section{Conclusion}

We fabricated $\mathrm{ZnO}$ films on glass substrates by the MOD method in the aim of developing a low cost preparation method. The films were physically examined by means of X-ray diffraction measurements and SEM observations. In the obtained $\mathrm{X}$-ray patterns, 5 typical diffraction structures were observed; polycrystalline $\mathrm{ZnO}$ was confirmed. The amount of $\mathrm{ZnO}$ does not depend on the temperature of heat treatment, but strongly depends on the time duration. The maximum amount of $\mathrm{ZnO}$ can be obtained at 40 minutes based on our results. The longer heat treatment conversely diminishes the amount. Since the FWHM is the smallest at 40 minutes at the same time, we can conclude that there exists an optimum time, 40 minutes in our experiments for example. From the viewpoint of FWHM in X-ray diffraction structures, more than $600^{\circ} \mathrm{C}$ is appropriate to the heat treatment. Finally, 


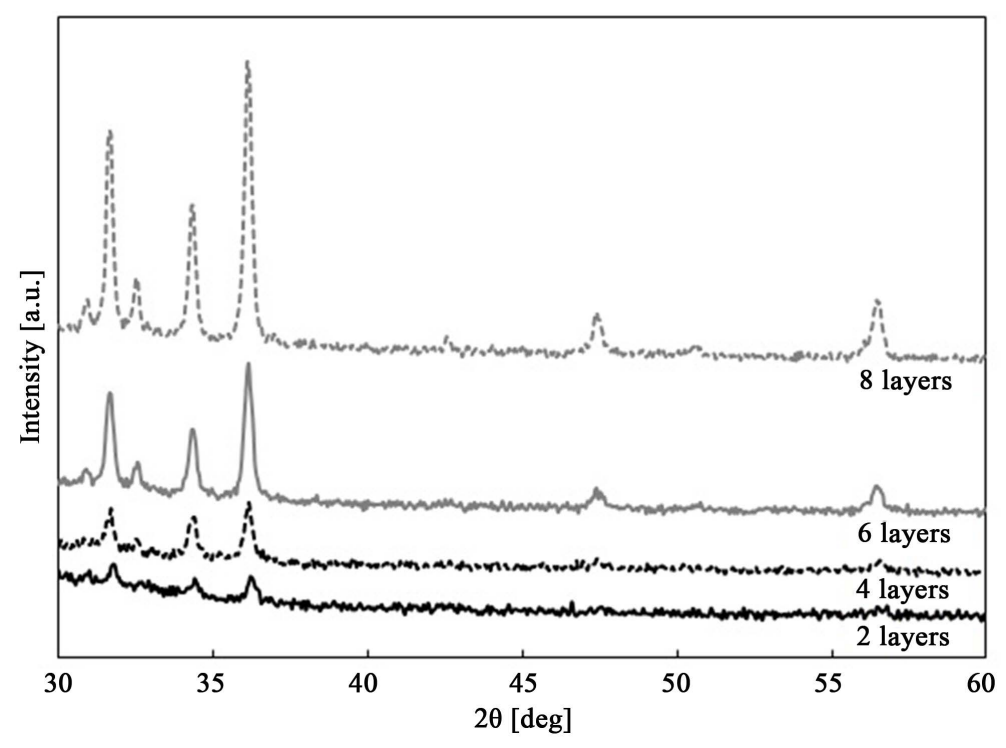

Figure 8. X-ray diffraction patterns from sample prepared at several repetition times of deposition.

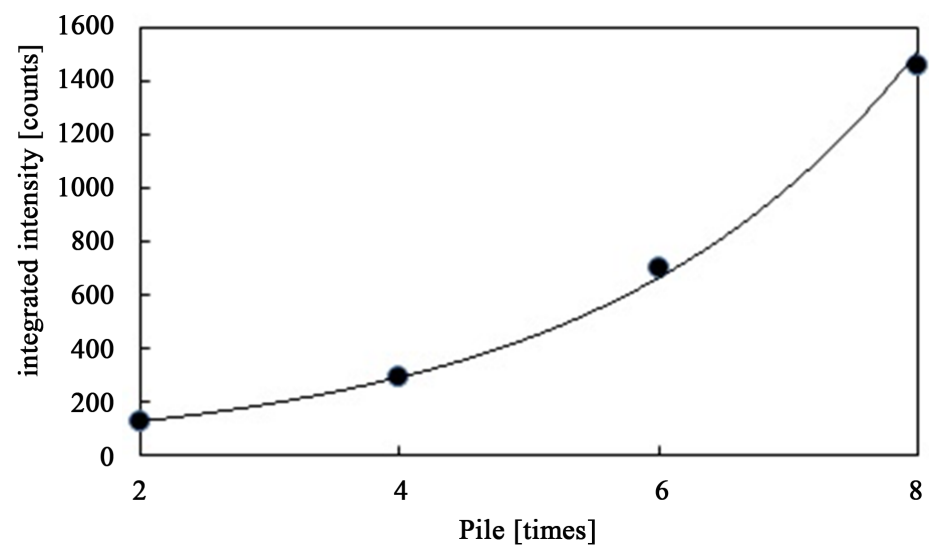

Figure 9. X-ray intensity of (101) diffraction from $\mathrm{ZnO}$ layer as a function of the repetition time of layer formations.

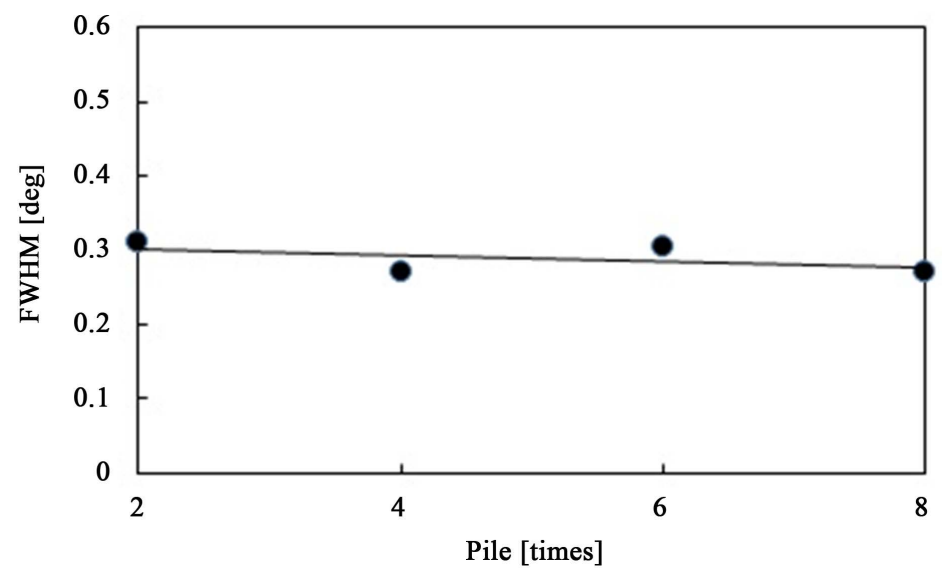

Figure 10. The FWHM of (101) X-ray diffraction structure from $\mathrm{ZnO}$ layer as a function of the repetition time of layer formations. 


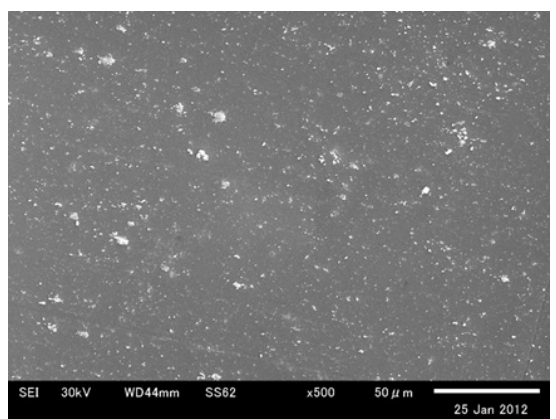

Figure 11. SEM photograph of the surface of 2-layer laminated sample.

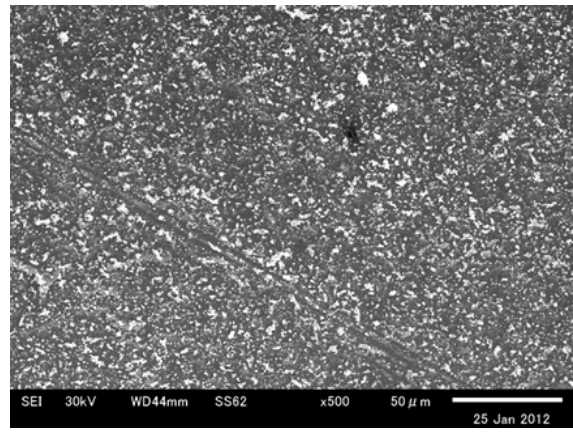

Figure 12. SEM photograph of the surface of 4-layer laminated sample.

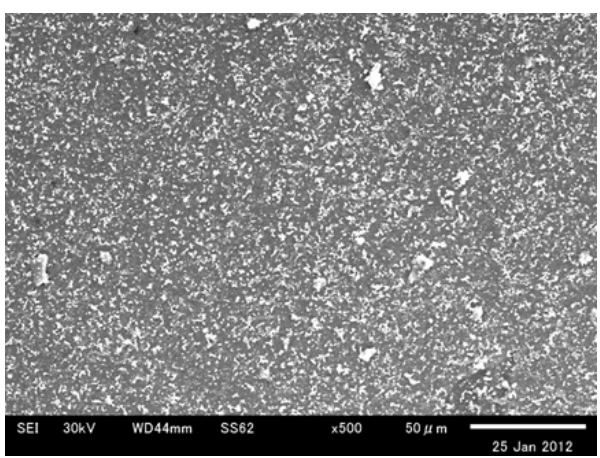

Figure 13. SEM photograph of the surface of 6-layer laminated sample.

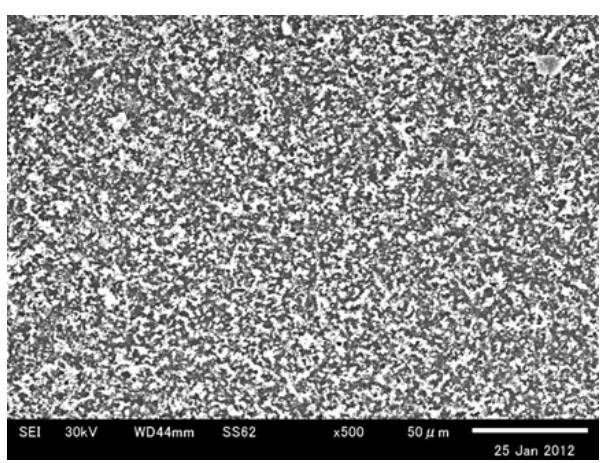

Figure 14. SEM photograph of the surface of 6-layer laminated sample. 
the overglaze production method is effective to form a thick film.

\section{References}

[1] Agura, H., Suzuki, A., Matsushita, T., Aoki, T. and Okuda, M. (2003) Low Resistivity Transparent Conducting AlDoped ZnO Films Prepared by Pulsed Laser Deposition. Thin Solid Films, 445, 263-267. http://dx.doi.org/10.1016/S0040-6090(03)01158-1

[2] Scheer, R., Walter, T., Shock, H.W., Fearheiley, M.L. and Lewerenz, H. (1993) CuInS2 Based Thin Film Solar Cell with 10.2\% Efficiency. Applied Physics Letters, 63, 3294-3296. http://dx.doi.org/10.1063/1.110786

[3] Nomura, K., Ohta, H., Ueda, K., Kamiya, T., Hirano, M. and Hosono, H. (2003) Thin-Film Transistor Fabricated in Single-Crystalline Transparent Oxide Semiconductor. Science, 300, 1269-1272. http://dx.doi.org/10.1126/science.1083212

[4] Fortunato, E.M.C., Barquinha, P.M.C., Pimentel, A.C.M.B.G., Gonçalves, A.M.F., Marques, A.J.S., Martins, R.F.P. and Pereira, L.M.N. (2004) Wide-Bandgap High-Mobility ZnO Thin-Film Transistors Produced at Room Temperature. Applied Physics Letters, 85, 2541-2543. http://dx.doi.org/10.1063/1.1790587

[5] Tsukazaki, A., Kubota, M., Ohtomo, A., Onuma, T., Ohtani, K., Ohno, H., Chichibu, S.F. and Kawasaki, M. (2005) Blue Light-Emitting Diode Based on ZnO. Japanese Journal of Applied Physics, 44, L643-L645. http://dx.doi.org/10.1143/JJAP.44.L643

[6] Ohta, H., Kawamura, K., Orita, M., Hirano, M., Sarukura, N. and Hosono, H. (2000) Current Injection Emission from a Transparent p-n Junction Composed of p-SrCu2O2/n-ZnO. Applied Physics Letters, 77, 475-477. http://dx.doi.org/10.1063/1.127015

[7] Golego, N., Studenikin, S.A. and Cocivera, M. (2000) Sensor Photoresponse of Thin-Film Oxides of Zinc and Titanium to Oxygen Gas. Journal of the Electrochemical Society, 147, 1592-1594. http://dx.doi.org/10.1149/1.1393400

[8] Martins, R., Fortunato, E., Nunes, P., Ferreira, I., Marques, A., Bender, M., Katsarakis, N., Cimalla, V. and Kiriakidis, G. (2004) Zinc Oxide as an Ozone Sensor. Journal of Applied Physics, 96, 1398-1408.

[9] Chou, T.P., Zhang, Q., Fryxell, G.E. and Cao, G.Z. (2007) Hierarchically Structured ZnO Film for Dye-Sensitized Solar Cells with Enhanced Energy Conversion Efficiency. Advanced Materials, 19, 2588-2592. http://dx.doi.org/10.1002/adma.200602927

[10] Özgür, Ü., Alivov, Y.I., Liu, C., Teke, A., Reshchikov, M.A., Dogan, S., Avrutin, V., Cho, S.-J. and Morkoç, H. (2005) A Comprehensive Review of ZnO Materials and Devices. Journal of Applied Physics, 98, Article ID: 041301. http://dx.doi.org/10.1063/1.1992666

[11] Guo, Q., Kume, Y., Tanaka, T., Nishio, M., Ogawa, H. and Yoshida, A. (2005) Strong Room-Temperature UV Luminescence from ZnO Grown by Metal Organic Decomposition. Japanese Journal of Applied Physics, 44, 8451-8452. http://dx.doi.org/10.1143/JJAP.44.8451

[12] Zou, Y., Wang, Y., Zhang, H., Chen, Z., Wang, J. and Li, Y. (2007) Thermochemical Process in Preparation of ZnO Film by TFA-MOD Method. Applied Surface Science, 253, 4356-4360. http://dx.doi.org/10.1016/j.apsusc.2006.09.044 
Scientific Research Publishing (SCIRP) is one of the largest Open Access journal publishers. It is currently publishing more than 200 open access, online, peer-reviewed journals covering a wide range of academic disciplines. SCIRP serves the worldwide academic communities and contributes to the progress and application of science with its publication.

Other selected journals from SCIRP are listed as below. Submit your manuscript to us via either submit@scirp.org or Online Submission Portal.
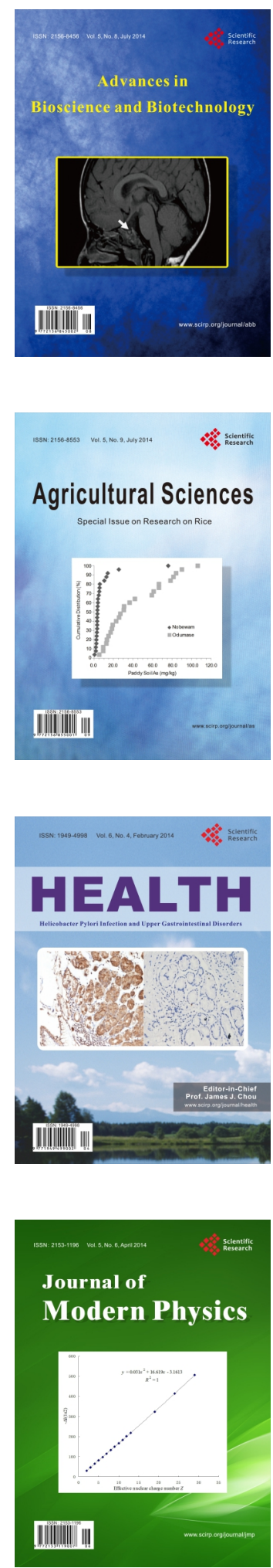
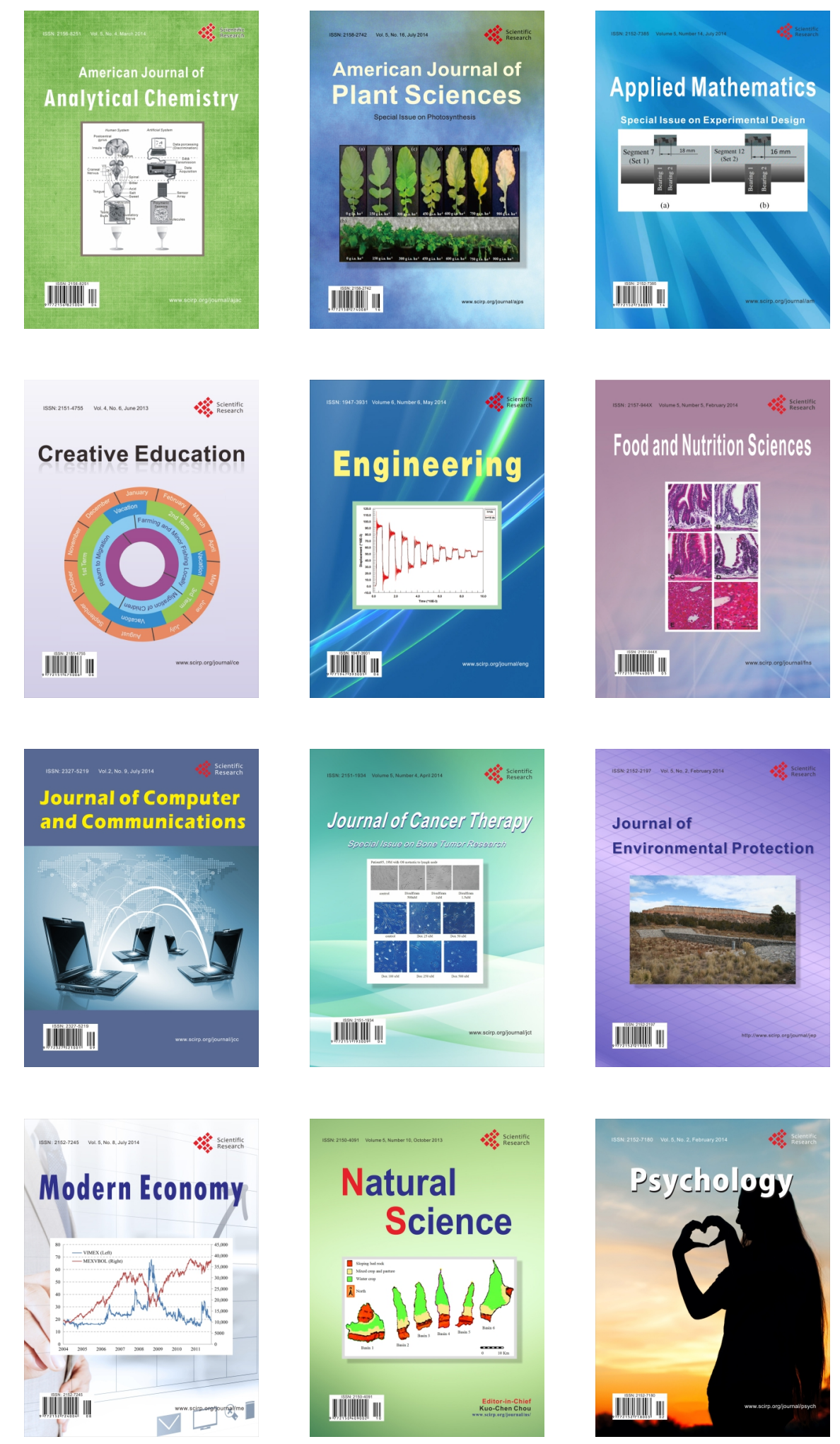